\title{
DIVERSIDADE DE LINGUAGEM NO TRABALHO DIDÁTICO
}

Música, texto jornalístico, texto didático e audiovisual ajudam a introduzir conteúdos sobre o ciclo da água e o tema transversal meio ambiente

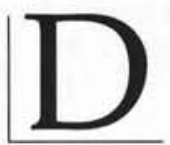

emos início ao trabalho a partir do planejamento para o primeiro bimestre letivo de 1998, realizado em conjunto pelos professores das quartas séries do ensino fundamental, no inicio do mês de março do mesmo ano. O planejamento tratou de Ciências Naturais e do tema transversal Meio Ambiente. O conteúdo do trabalho, a ser desenvolvido pelo professor, propôs estabelecer relação entre troca de calor e mudanças de estados físicos da água para fundamentar explicações acerca do ciclo da água, além de tratar de problemas relevantes, tais como escassez e preservação.

Ao desenvolver o planejamento, as atividades com o conteúdo de Ciências Naturais e o tema transversal Meio Ambiente tiveram como objetivo levar o aluno a entender o ciclo da água; discutir a presença da água no planeta e suas transformações, como também a importância, necessidade e urgência de o homem usar racionalmente a água existente; promover o trabalho em grupo, despertando na criança a sociabilidade, o diálogo com argumentação, crítica, exposição de idéias e conceitos adquiridos.

Começamos o trabalho com os alunos a partir da audição, canto e posterior leitura e interpretação da letra da canção Planeta Água, de Guilherme Arantes.

\section{Planeta água}

Cantor e compositor: Guilherme Arantes

Água que nasce na fonte serena do mundo e que abre um profundo grotão. Água que faz inocente 
riacho e desagua

na corrente do ribeirão.

Águas escuras dos rios que levam a fertilidade ao sertão.

Águas que banham aldeias

e matam a sede da população.

Águas que caem das pedras

no véu das cascatas,

ronco de trovão.

E depois dormem tranqüilas

no leitos dos lagos,

no leito dos lagos.

Água dos igarapés,

onde Iara mãe d'água

é misteriosa canção.

Água que o sol evapora

pro céu vai embora,

virar nuvens de algodão.

Gotas de água da chuva,

alegre arco-íris sobre a plantação.

Gotas de água da chuva,

tão tristes, são lágrimas da inundação.

Águas que movem moinhos

são as mesmas águas

que encharcam o chão

e sempre voltam humildes

pro fundo da terra,

pro fundo da terra.

Terra, planeta água

Terra, planeta água

Terra, planeta água

Após o trabalho de sensibilização a partir da música, buscou-se tratar o tema da água a partir do texto informativo. Distribuíram-se aos alunos cópias da reportagem do jornal O Estado de S. Paulo, de 23/03/98, sobre o dia mundial da água. Os alunos leram a notícia, discutiram-se as dúvidas de vocabulário e de conteúdo. Várias perguntas foram anotadas para serem respondidas a partir da leitura de fonte de informação mais especializada sobre o tema.

\section{Brasil tem nova legislação}

Falta de água tende a produzir conflitos no próximo século

Ivana Diniz Machado

Especial para o Estado

BRASÍLIA - A partir do século 21, o mundo poderá conhecer um novo tipo de guerra, provocada pela falta de água. A explosão populacional, com o aumento da demanda, compromete o ciclo natural de renovação da água.

Quem quiser utilizar o potencial de estoques, para matar a sede ou irrigar, terá de pagar. A ameaça é realidade não só em países como Israel e Jordânia (que compartilham a oferta do minguado Rio Jordão). A guerra já começou aqui no Brasil, onde estão nada menos que $10 \%$ dos 8,5 milhões de quilômetros cúbicos da água potável do Planeta.

O problema é que $70 \%$ dessa reserva hídrica está concentrada na Amazônia. Em muitas regiões, especialmente no Sudeste mais industrializado, a oferta natural é parca e de má qualidade. No Sul, pequenos proprietários de terras irrigadas e indústrias entram em litígio pelas barragens e uso dos mananciais de grandes e pequenos rios. No Nordeste, o governo tenta dessalinizar as cacimbas para enfrentar a seca crônica. A legislação brasileira sobre o assunto, embora não seja ruim, é dispersa e tem mais de 60 anos ( julho de 1934).

Empurrado pelas pressões internas e internacionais, o Congresso aprovou em 1996 a Política Nacional de Recursos Hídricos, sancionada em janeiro de 1997 pelo presidente da República. A lei trouxe algumas revoluções conceituais, despertou polêmicas e causou reações. Um ano depois ainda aguarda regulamentação para ser aplicada.

A Secretaria de Recursos Hídricos, do Ministério do Meio Ambiente, dos Recursos Hídricos e da Amazônia Legal, está encarregada de criar a nova lei, que dá prioridade ao abastecimento humano e animal. Mas, para isso, precisa criar o Conselho Nacional de Recursos Hídricos (normatizador da política) e os executores, os comitês de bacias hidrográficas. Ontem, em São Paulo, num gesto simbólico, ambientalistas retiraram 1 tonelada de lixo da Represa Billings. 
Para aprofundar as informações já obtidas e ampliar o conhecimento sobre a água e sua importância para a vida e o meio ambiente, selecionaram-se capítulos dos livros Água, lixo e meio ambiente, Aventuras de uma gota d'água e Poluição das águas $^{1}$. Os alunos foram reunidos em grupos de seis crianças e leram os textos dos capítulos selecionados, discutiram em grupo e, posteriormente, a discussão foi feita com toda a classe junto com a professora. Várias dúvidas foram sanadas e outras foram listadas para serem trabalhadas a partir da assistência aos vídeos: Meteorologia, da TV Escola/MEC-, CNDP/França/1995; Aventura visual, da Editora Globo, 1997; Rios e Lagos - série Grande show de animais - peixes e corais, da TV Escola/MEC. Após cada projeção, realizou-se um debate sobre o ciclo da água, sua presença no planeta, suas transformações e sua importância para a vida.

\section{DIFERENTES LINGUAGENS E PONTOS DE VISTA}

Levar o aluno a interessar-se pelo conteúdo e sensibilizá-lo para receber as diferentes informações oferecidas foram as estratégias adotadas na escolha dos tipos de textos a serem trabalhados. Da sensibilização através da música à introdução de temáticas do cotidiano, através do texto jornalístico, até os conteúdos organizados pedagogicamente nos textos dos livros e do audiovisual dos filmes, tem-se um percurso com diferentes atrativos, acionando o processo perceptivo da criança e seu engajamento para a aquisição do conhecimento.

$\mathrm{Na}$ fase final do projeto, buscou-se trabalhar a criatividade dos alunos e consolidar os conceitos ministrados, através da leitura e dramatização da fábula de Millôr Fernandes, A causa da chuva.

\section{A causa da chuva}

\section{de Millôr Fernandes}

Não chovia há muitos e muitos meses, de modo que os animais ficaram inquietos. Uns diziam que ia chover logo, outros diziam que ainda ia demorar. Mas não chegavam a uma conclusão.

- Chove só quando a água cai do telhado do meu galinheiro - esclareceu a galinha.

- Ora, que bobagem! - disse o sapo dentro da lagoa. - Chove quando a água da lagoa começa a borbulhar suas gotinhas.

- Como assim? - disse a lebre. - Está visto que só chove quando as folhas das árvores começam a deixar cair as gotas d'água que têm dentro.

Nesse momento começou a chover

- Viram? - gritou a galinha. - O telhado do meu galinheiro está pingando. Isso é chuva.

- Ora, não vê que a chuva é a água da lagoa borbulhando? - disse o sapo.

- Mas, como assim? - tornou a lebre. Parecem cegos! Não vêem que a água cai das folhas das árvores?

Moral: Todas as opiniões estão erradas.

Depois da leitura individual do texto, explicou-se que fábula é a narração que nos traz ensinamentos e que suas personagens, geralmente, são animais que agem como seres humanos. A partir daí, foram dadas aos alunos as seguintes ordens:

- invente uma outra personagem que explicará aos animais a causa da chuva;

1. CETESB. Água, lixo e meio ambiente. 2.ed. São Paulo: 1988. BRANCO, S.M. Aventuras de uma gota d'água. Coleção Viramundo. 44. ed. São Paulo: Moderna, 1990. MAGOSSI, L.R. e BONACELLA, P.H. Poluição das Águas. Coleção Desafios. 6.ed. São Paulo: Moderna, 1991. 


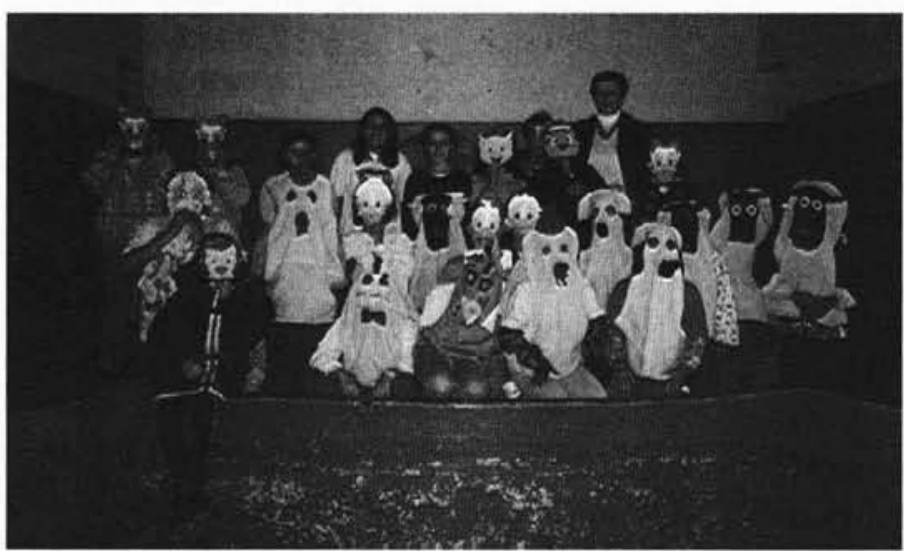

Prof. Maria Ângela e seus alunos da quarta-série C, 1998

dos capacitaram-se para conhecer e compreender os conceitos trabalhados em sala de aula.

\section{Grupo 1:}

"Apareceu o cavalo, no meio da conversa dos bichos e explicou:

- A água evapora-se das poças de água, dos rios e mares, sobe para o céu e as nuvens ficam pesadas e caem em

- dramatize com os amigos do grupo a fábula A causa da chuva.

Dividiram-se os alunos em seis grupos para dramatizarem a fábula. Os grupos foram compostos de cinco elementos: três personagens já existentes, um narrador e mais uma personagem criada pelo grupo, com a tarefa de explicar a correta causa da chuva. Cada grupo reuniu-se na escola, para divisão dos papéis, criação de mais uma personagem, ensaios, caracterização (fantasias).

Os grupos apresentaram a fábula, no palco da escola. Eles foram sorteados para a apresentação em dias diferentes da semana, no horário da aula de Língua Portuguesa. Após cada apresentação, em círculo, os alunos e o professor avaliaram o desempenho de cada um e a explicação do ciclo da água. Quando todos os grupos já haviam dramatizado, eles se auto-avaliaram: a melhor apresentação, a melhor explicação, o melhor ator e narrador.

Conforme havia sido solicitado, cada grupo criou um quarto personagem para explicar o ciclo da água em nosso planeta. A seguir, através das falas que os alunos criaram, pode-se perceber como to- forma de chuva". ".

\section{Grupo 2:}

"De repente aparece um boi e começa a explicar como se forma a chuva:

- A chuva se forma assim: quando eu estou pastando e começa a chover, a grama do pasto fica encharcada. Depois vem o sol evapora essa água em forma de gotinhas bem pequenas que sobem para o céu. Essas gotinhas formam uma nuvem, carregam tanto essa nuvem, ela fica bem pesada e descarrega suas águas em forma de chuva. E encharca o pasto novamente".

\section{Grupo 3:}

"Chega o cachorro e diz:

- Vocês estão enganados! A chuva é formada quando o sol esquenta as águas dos rios, lagos e mares. Aí sobe para o céu em forma de vapor, formando uma nuvem, que fica muito pesada e ela solta suas gotinhas em forma de chuva".

\section{Grupo 4:}

"No meio da floresta, aparece a vovó Donalda e diz:

- Não, todos vocês estão errados. A 
chuva é formada pelas águas dos rios e mares, que esquentam com o calor do sol, evaporam, sobem para o céu, formam as nuvens e descem em forma de chuva".

\section{Grupo 5:}

"Todos estavam errados e apareceu o cavalo que explicou:

- É muito simples, a chuva é formada por gotinhas que caem do céu. Elas vão para os rios, lagos e mares. O calor do sol esquenta as águas desses lugares, elas evaporam. Sobem novamente para o céu em forma de gotinhas pequenas, formam uma nuvem bem pesada e caem na terra em forma de chuva".

\section{Grupo 6:}

"Apareceu o burro e falou:

- Vocês não sabem de nada. Eu estava andando, quando tropecei num livro e comecei a lê-lo. Nele estava explicando que as águas dos rios, lagos e mares se evaporam com o calor, vão para o céu e trans-

Resumo: Professora do ensino fundamental narra experiência realizada com conteúdo de ciências naturais, sobre o ciclo da água, e o tema transversal Meio Ambiente. Ela desenvolve atividades, iniciando pela sensibilização das crianças através de música, para passar ao texto jornalístico e, só depois, ao texto didático, audiovisual e literário. As crianças cantam, lêem, discutem, assistem, debatem e interpretam em torno dos temas ciclo da água e meio ambiente. Como atividade para avaliação das crianças, propõe a dramatização da fábula $A$ causa da chuva, de Millôr Fernandes. Os alunos criam uma nova personagem e 0 texto explicativo que conclui a fábula.

Palavras-chave: ciclo da água, meio ambiente, ensino fundamental, planejamento, tema transversal formam-se em nuvens. Elas caem em forma de chuva na terra".

\section{AVALIAÇÃO DO TRABALHO}

Os alunos demonstraram entusiasmo, interesse e responsabilidade ao dramatizarem a fábula e ao criarem o texto para a explicação correta do ciclo da água.

As fontes de informações oferecidas à classe, motivaram os alunos a construir conceitos próprios e corretos.

$\mathrm{Na}$ roda de avaliação, foram discutidos muitos assuntos referentes à água existente em nosso planeta: sua importância, interferência do homem no ambiente e suas conseqüências; suas transformações.

Durante a roda de avaliação, o professor organizou na lousa um texto síntese a partir da intervenção dos alunos sobre os conceitos e informações adquiridos. O texto síntese, resultado da participação coletiva dos alunos, foi copiado no caderno.

\section{(Language diversity in teaching)}

Abstract: An elementary school teacher narrates an experience carried out with natural science content, about the water cycle, and the transversal Environmental theme. She develops activities, starting by making kids more sensible through music, going on to the journalistic text and only then to didactic texts, audiovisual and literary content. The kids sing, read, discuss, watch, debate and interpret themes dealing with the water cycle and the environment. As an activity to evaluate the children, she proposes dramatizing Millôr Fernandes' $A$ causa da chuva tale. The students create a new character and the explanatory text that concludes the tale.

Key words: water cycle, environment, elementary teaching, planning transversal theme 